\title{
Systemic capillary leak syndrome
}

INSERM

\section{Source}

INSERM. (1999). Orphanet: an online rare disease and orphan drug data base. Systemic capillary leak syndrome. ORPHA:188

Systemic capillary leak syndrome (SCLS) is a severe systemic disease due to increased capillary permeability, characterized by episodes of hypotension, edema and hypovolemia. 